\title{
LIMIT LOAD SOLUTIONS FOR SEN(T) SPECIMENS - 2D AND 3D PROBLEMS
}

\author{
M. GRABA \\ Kielce University of Technology \\ Faculty of Mechatronics and Mechanical Engineering \\ Department of Manufacturing Engineering and Metrology \\ Al. 1000-lecia PP 7, 25-314 Kielce, POLAND \\ E-mail:mgraba@tu.kielce.pl
}

\begin{abstract}
This paper deals with the limit load solutions for SEN(T) specimens under plane stress and plane strain conditions. The existing solutions are verified using the Finite Element Method and extended to 3D cases. The numerical results can be used to assess the strength of a structural element with a defect. This paper is a verification and extension of the author's previous paper [2].
\end{abstract}

Key words: $\operatorname{SEN}(\mathrm{T})$, limit loads, FEM, fracture.

\section{Introduction (based on [1-4])}

The problem of limit loads is still valid in fracture mechanics. It has been discussed extensively by a number of researchers. Limit loads are required to determine the characteristic time for a failure of a structure with a crack subjected to external loads. The limit load can be defined as the load resulting in a state where the uncracked ligament of the specimen (or a structural element) is plasticized; this means that the effective stress calculated according to the Huber-Mises-Hencky hypothesis is equal to or greater than the yield stress [1-4]. It should be noted that this condition can be satisfied for specimens (structural elements) modeled as ones made of an elastic-perfectly plastic material. The limit load is determined by observing the growth of the plastic zone near the crack tip and analyzing the plots showing the relationship between the force and the load line displacement. The plateau generally suggests that full plasticity has occurred in the specimen (element), i.e., the limit load has been achieved [1-4]. For this step of the determination of limit loads, the "twice elastic slope" method is often used.

Limit loads are well-suited for assessing the strength of structures with defects. The assessment is based on the analysis of, for example, Failure Assessment Diagrams or Crack Driving Force diagrams [1, 5]. Limit loads can be used in hybrid solutions to estimate the J-integral, the crack opening displacement and the load line displacement, which are dependent on the external load, the material characteristics and the element geometry. [5]. It is thus important to determine limit loads by employing adequate formulae without the need to create a finite element model or conduct numerical calculations.

There are many solutions available for SEN(T) plates (Fig.1) which allow us to estimate the limit load. The most famous is the EPRI solution [5], which requires calculating the limit load per unit thickness

$$
P_{0}= \begin{cases}1.455 \cdot \eta \cdot b \cdot \sigma_{0} & \text { for plane strain } \\ 1.072 \cdot \eta \cdot b \cdot \sigma_{0} & \text { for plane stress }\end{cases}
$$


where $P_{0}$ is the limit load, $\sigma_{0}$ is the yield stress and $\eta$ is the function dependent on the crack length $a$ and the length of the uncracked ligament $b$ of the specimen $(b=W-a)$

$$
\eta=\left[1+(a / b)^{2}\right]^{0.5}-(a / b)
$$

The solution proposed by the EPRI [5] has been modified many times. In 1988, Miller [6] suggested that it should be modified as follows

$$
P_{0}= \begin{cases}1.155 \cdot B \cdot W \cdot \sigma_{0} \cdot(1-a / W) & \text { for plane strain } \\ 1 \cdot B \cdot W \cdot \sigma_{0} \cdot(1-a / W) & \text { for plane stress }\end{cases}
$$

where $B$ is the specimen thickness.

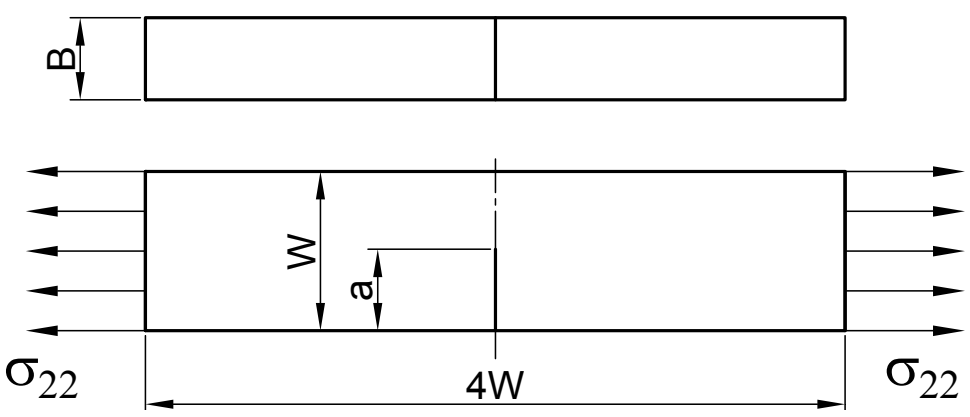

Fig.1. Single edge notched specimen in tension $[1-2,4]$.

The next modification was made in 2013 [2]

$$
P_{0}= \begin{cases}B \cdot \sigma_{0} \cdot[1241.1 \cdot W \cdot(1-a / W)+0.9048] & \text { for plane strain } \\ B \cdot \sigma_{0} \cdot[1051.8 \cdot W \cdot(1-a / W)+1.4785] & \text { for plane stress }\end{cases}
$$

where the yield stress $\sigma_{0}$ should be expressed in [MPa], the geometrical dimensions (the crack length $a$, the specimen width $W$ and the specimen thickness $B$ ) in $[\mathrm{m}]$ and the limit load $P_{0}$ to be calculated in $[k N]$.

It can be seen that Eqs (1.1)-(1.4) are strongly dependent on the geometry of the SEN(T) specimens, which can be expressed by the length of the uncracked ligament. The formulae offer different accuracy for SEN(T) specimens with standard dimensions. Reference [7] indicates that the above solutions are not suitable for the analysis of miniature SEN(T) specimens. In this interesting paper [7], the authors discuss and compare the results of their numerical calculations and propose a new formula to determine limit loads for SEN(T) specimens

$$
P_{0}= \begin{cases}B \cdot \sigma_{0} \cdot[1154.449 \cdot W \cdot(1-a / W)+0.03] & \text { for plane strain } \\ B \cdot \sigma_{0} \cdot[999.965 \cdot W \cdot(1-a / W)+0.012] & \text { for plane stress }\end{cases}
$$


where the yield stress $\sigma_{0}$ should be expressed in [MPa], the geometrical dimensions (the crack length $a$, the specimen width $W$ and the specimen thickness $B$ ) in $[\mathrm{m}]$ and the limit load $P_{0}$ to be calculated in $[k N]$.

Formula (1.5) proposed in [7] requires numerical calculations for plane stress and plane strain conditions, with the assumption of small strains and small displacements as well as large strains and large displacements. All the above equations used for calculating limit loads are valid for plane stress and plane strain conditions. The equations take into consideration the specimen thickness $B$, but they do not apply to structural elements characterized by a specific thickness. For this reason, the concept of limit loads will be extended in this paper to three-dimensional cases.

\section{Methodology - geometry, material and numerical analysis (based on [1-4])}

\subsection{Geometry and material of SEN(T) plates}

The numerical analysis aimed at extending the limit load solutions to 3D cases. It was carried out for SEN(T) specimens shown in Fig.1. The numerical calculations were performed using the Finite Element Method (FEM). The SEN(T) plates had a width of $W=40 \mathrm{~mm}$ and a length $L$ satisfying the condition that $L \geq 2 W$. The numerical analysis was carried out for four relative crack lengths $(a / W=\{0.05,0.20,0.50,0.70\})$ and six specimen thicknesses $(B=\{2,4,8,16,25,40\} \mathrm{mm})$. The different values of the relative crack length guarantee different levels of the "in-plane" constraints, which affect the fracture toughness and stress distribution near the crack tip [1,4]. This wide range of specimen thicknesses guarantees that the analysis is well suited for structural elements characterized by intermediate stress state between the plane strain and plane stress. The total length of the plate will be $L=176 \mathrm{~mm}$. For the plane stress and plane strain analysis performed according to the ADINA recommendations [8,9], the specimen thickness will be $B=1 \mathrm{~mm}$ and $B=1 m$, respectively.

The numerical analysis was performed for an elastic-perfectly plastic material with Young's modulus $E=206 \mathrm{GPa}$ and Poisson's ratio $v=0.30$. Four values of the yield stress were taken into consideration: $\sigma_{0}=\{315,500,1000,1500\} \mathrm{MPa}$. The numerical calculations were conducted for a wide range of yield stress values, which allows us to model materials such as ferritic steels, structural steels and high strength steels [4].

\subsection{Details of the numerical calculations $-2 D$ and $3 D$ cases}

All the numerical calculations were performed using ADINA SYSTEM 8.7.3 [8,9]. Small strain and small displacement options were considered for the plane strain, plane stress and 3D cases. The same FEM model was used to analyze the plate behavior under plane stress and plane strain conditions; however, different types of finite elements and different types of interpolation in the finite element were taken into account. A different finite element mesh was created for the 3D analysis.

The analysis of the plane stress and plane strain conditions involved using a finite element mesh with nine-node plane strain (with mixed formulation of the interpolation) or plane stress (with default formulation of the interpolation) elements $[2,3,10]$. Half of the specimen was modeled; the existing axis of symmetry was used. For the 3D analysis, only a quarter of the plate was modeled because of the symmetry and the finite element mesh was filled using eight-node three-dimensional brick elements with "mixed" type of the interpolation. ADINA $[8,9]$ recommends that elements in tension should be analyzed using eight-node brick finite elements for 3D cases and nine-node plane finite elements for the plane stress and plane strain options $[2,3,10]$. Each finite element has eight points of numerical integration for $3 \mathrm{D}$ cases and nine points of numerical integration for plane states. 
a)

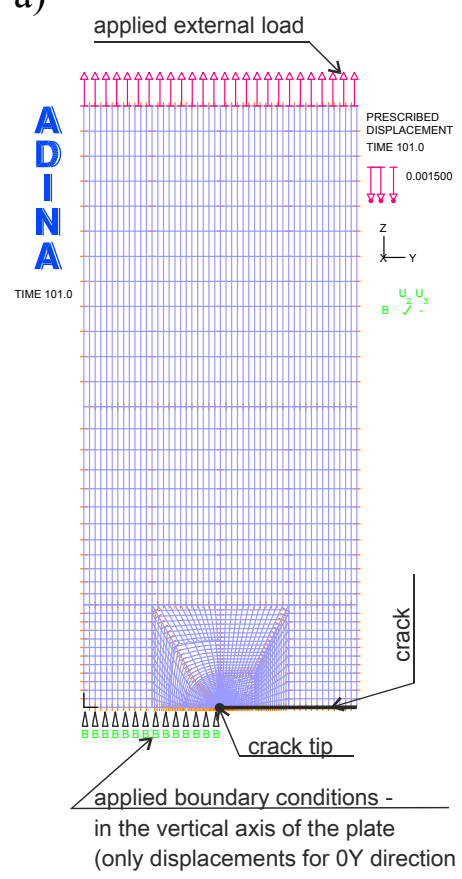

b)

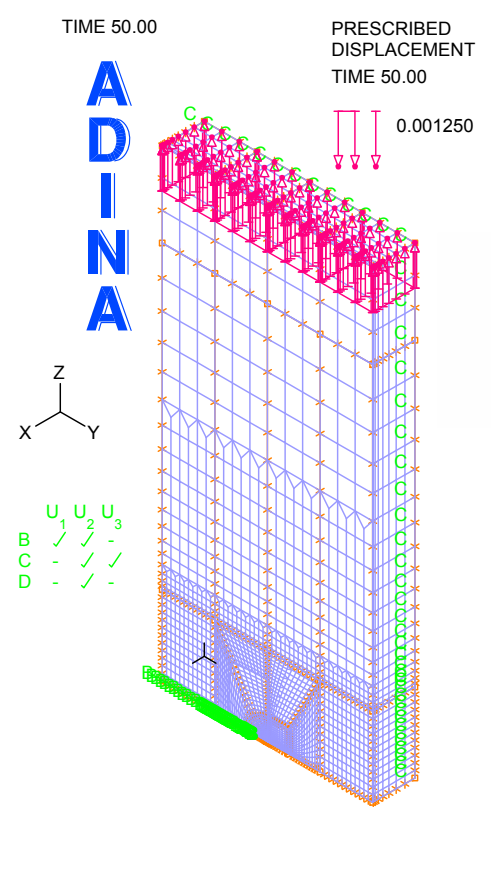

c)

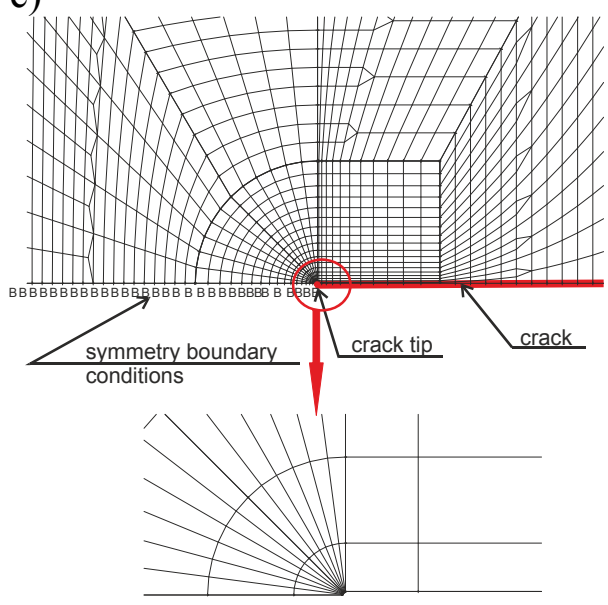

Fig.2. Numerical models of the SEN(T) specimens used in the analysis of (a) the plane stress and plane strain conditions and (b) the 3D cases. Finite elements of the mesh near the crack tip (c) $[2,3,10]$.

The numerical models were based on some reliable assumptions provided in [2, 3, 11-13]. For all the models considered, the size of the finite elements in the radial direction decreased towards the crack tip, while the size of the elements in the angular direction remained constant. The crack tip region was modeled using $36 \div 50$ semicircles $[2,3]$. The first of them was at least $20 \div 50$ times smaller than the last one. It also means that the finite element closest to the crack tip is $3076 \div 10210$ times smaller than the specimen width. The crack tip was modeled as a quarter of an arc with a radius of $r_{w}=(1 \div 5) \cdot 10^{-6} \mathrm{~m}$ (which is $(1 / 40000 \div 1 / 800) \times W)[2,3]$. The whole SEN(T) specimen was modeled using $3149 \div 3428$ finite elements and $12803 \div 13921$ nodes (plane stress and plane strain options) and 15552 finite elements and 18018 nodes (3D cases).

Two specimen thicknesses, i.e., $B=1 \mathrm{~mm}$ and $B=1 \mathrm{~m}$, were considered for plane strain and plane stress, respectively. All the models used in the plane stress and plane strain analysis were built according to the guidelines provided in the literature by Brocks et al. [11-12] and in [13]. In the 3D analysis, the mesh consists of nine layers of 3D brick elements (across half of the thickness of the SEN(T) specimen). The layer interface is located at $x_{3} / B=\{0.000 ; 0.119 ; 0.222 ; 0.309 ; 0.379 ; 0.434 ; 0.472 ; 0.483 ; 0.494 ; 0.500\}$, where $x_{3}$ denotes the Cartesian coordinate in the thickness direction [2-4]. The layer in the center of the specimen $\left(x_{3} / B=0\right)$ is from twenty to fifty times thicker than that near the free surface $\left(x_{3} / B=0.5\right)$. This means that the layers become thinner as the free surface is approached [2-4].

In all the case studies, the external load was applied to one edge of the specimen as a displacement increasing with time. To summarize, the analysis was performed using 32 plane models and 96 3D models of the SEN(T) specimens. An extensive program of numerical calculations may allow us to assess the limit loads for plates with different crack lengths (which determine the level of the in-plane constraints), different thicknesses (which determine the level of the out-of-plane constraints) and different yield stresses (which allow us to compare the actual structural materials with one of the model materials). Figure 2 presents the numerical models of the SEN(T) specimens used in the analysis. 


\section{Numerical results}

\subsection{Numerical results for $2 \mathrm{D}$ cases - plane stress and plane strain}

The numerical determination of the limit loads was based on the observations of the increasing plastic zone and the analysis of the plots showing the relationship between the external load and the load line displacement with the use of the "twice elastic slope" method. The values of the limit load obtained for plane stress and plane strain are presented in Tab.1.

Table 1. Limit load values calculated numerically for SEN(T) specimens under plane stress and plane strain conditions.

\begin{tabular}{|c|c|c|c|c|c|c|c|c|}
\hline \multirow{4}{*}{$a / W$} & \multicolumn{4}{|c|}{ plane stress $B=1 \mathrm{~mm}$} & \multicolumn{4}{|c|}{ plane strain $B=1 m$} \\
\cline { 2 - 9 } & $P_{0}[\mathrm{kN}]$ & $P_{0}[\mathrm{kN}]$ & $P_{0}[\mathrm{kN}]$ & $P_{0}[\mathrm{kN}]$ & $P_{0}[\mathrm{kN}]$ & $P_{0}[\mathrm{kN}]$ & $P_{0}[\mathrm{kN}]$ & $P_{0}[\mathrm{kN}]$ \\
& $\sigma_{0}=315$ & $\sigma_{0}=500$ & $\sigma_{0}=1000$ & $\sigma_{0}=1500$ & $\sigma_{0}=315$ & $\sigma_{0}=500$ & $\sigma_{0}=1000$ & $\sigma_{0}=1500$ \\
& $\mathrm{MPa}$ & $\mathrm{MPa}$ & $\mathrm{MPa}$ & $\mathrm{MPa}$ & $\mathrm{MPa}$ & $\mathrm{MPa}$ & $\mathrm{MPa}$ & $\mathrm{MPa}$ \\
\hline 0.05 & 11.94977 & 18.98046 & 37.96092 & 56.94139 & 13699.98 & 21708.00 & 43377.28 & 64794.47 \\
\hline 0.20 & 9.915604 & 15.74087 & 31.45846 & 47.19846 & 11331.73 & 18055.27 & 36037.39 & 54059.22 \\
\hline 0.50 & 6.107639 & 9.718953 & 19.39923 & 29.10425 & 6783.191 & 10760.62 & 21464.08 & 32196.26 \\
\hline 0.70 & 3.67877 & 5.830158 & 11.66481 & 17.49132 & 4035.573 & 6456.543 & 12852.43 & 19237.46 \\
\hline
\end{tabular}

a)

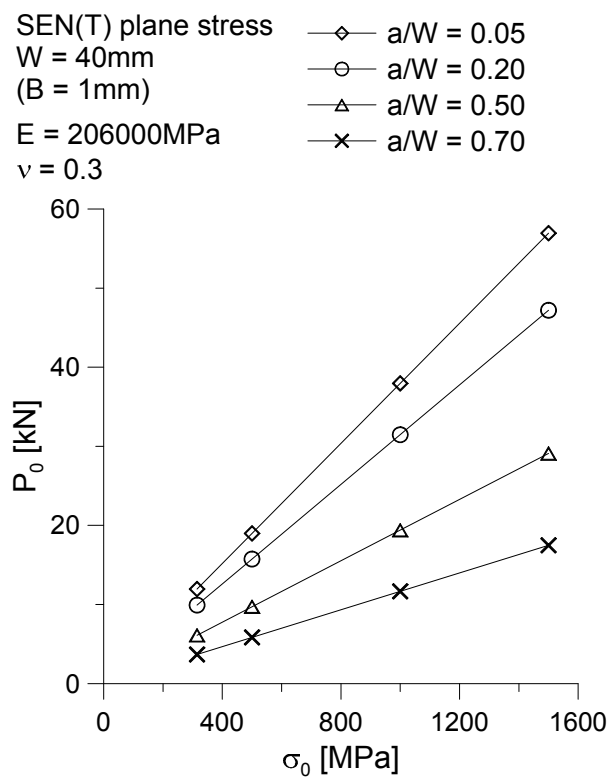

b)

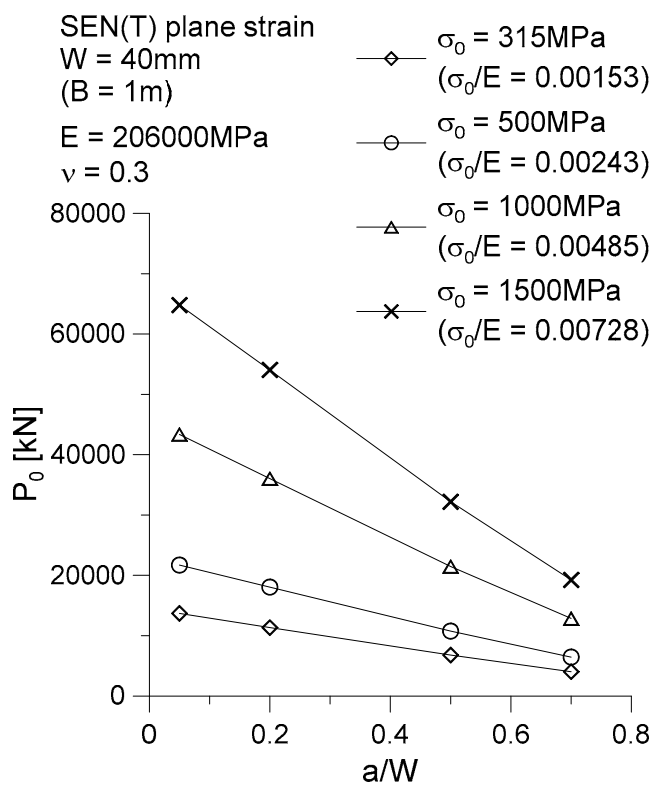

Fig.3. Influence of the relative crack length and the yield stress on the limit load for SEN(T) plates under (a) plane stress and (b) plane strain conditions.

Figures 3 shows the relationship between the relative crack length, the yield stress and the limit load. From the analysis of the numerical results a few obvious, almost natural conclusions, can be drawn; they were presented in [2]. The values of the limit load are greater for the plane strain cases than for the plane stress cases if the same value (the reference value) of the specimen thickness is used [2]. The higher the values of the yield stress, the greater the values of the limit load [2]. An increase in the crack length causes a decrease in the limit load. The analysis of the numerical results indicates that the limit load is proportionally dependent on the yield stress and the relative crack length. The results were compared with those obtained from Eq.(1.5) [7] - see Tab.2. 
Table 2. Comparison of the numerical results for the plane stress and plane strain conditions with those obtained from Eq.(1.5) [7] $\left.-\Delta_{P 0}=\left(P_{O_{-} F E M}-P_{O_{-} E Q(5)}\right) / P_{O_{-} F E M}\right) \cdot 100 \%$.

\begin{tabular}{|c|c|c|c|c|c|c|c|c|}
\hline \multirow{3}{*}{$a / W$} & \multicolumn{4}{|c|}{ plane stress $B=1 m m$} & \multicolumn{4}{c|}{ plane strain $B=1 m$} \\
\cline { 2 - 9 } & $\begin{array}{c}\Delta_{P 0} \\
\sigma_{\sigma}=315 \mathrm{MPa}\end{array}$ & $\begin{array}{c}\sigma_{P}=500 \mathrm{MPa} \\
\sigma_{0}=1000 \mathrm{MPa}\end{array}$ & $\begin{array}{c}\Delta_{P 0} \\
\sigma_{0}=1500 \mathrm{MPa}\end{array}$ & $\begin{array}{c}\Delta_{P 0} \\
\sigma_{0}=315 \mathrm{MPa}\end{array}$ & $\begin{array}{c}\Delta_{P 0} \\
\sigma_{0}=500 \mathrm{MPa}\end{array}$ & $\begin{array}{c}\Delta_{P 0} \\
\sigma_{0}=1000 \mathrm{MPa}\end{array}$ & $\begin{array}{c}\Delta_{P 0} \\
\sigma_{0}=1500 \mathrm{MPa}\end{array}$ \\
\hline 0.05 & $0 \%$ & $0 \%$ & $0 \%$ & $0 \%$ & $-1 \%$ & $-1 \%$ & $-1 \%$ & $-2 \%$ \\
\hline 0.20 & $-2 \%$ & $-2 \%$ & $-2 \%$ & $-2 \%$ & $-3 \%$ & $-2 \%$ & $-3 \%$ & $-3 \%$ \\
\hline 0.50 & $-3 \%$ & $-3 \%$ & $-3 \%$ & $-3 \%$ & $-7 \%$ & $-7 \%$ & $-8 \%$ & $-8 \%$ \\
\hline 0.70 & $-3 \%$ & $-3 \%$ & $-3 \%$ & $-3 \%$ & $-8 \%$ & $-8 \%$ & $-8 \%$ & $-8 \%$ \\
\hline
\end{tabular}

As can be seen, the difference between the FEM solution and the solution presented in [7] does not exceed $3 \%$ when the plates are under plane stress conditions. For plates with short $(a / W=0.20)$ or very short cracks $(a / W=0.05)$ under plane strain conditions, the difference is equal to or less than $3 \%$. For plates with a normalized crack length $(a / W=0.50)$ or with very long cracks $(a / W=0.70)$, the differences are greater. This may result from the different assumption made in this study and that described in [7] concerning the ratio between the width and the length of the plate. In the numerical program used in this study the ratio was $W / L=0.23$ while that considered in [7] was $W / L=0.30$. The results obtained by numerical calculations for elements in close proximity to the edge of the plate can be different, as shown by Kim in [14, 15]. Similar differences are observed between the FEM-based results presented here and those obtained from Miller's formula - Eq.(1.3) [6]. It can be concluded that the values of the limit load guarantee conservative results.

\subsection{Numerical results for 3D cases}

The behavior of the SEN(T) plates reaching full plasticity, which corresponds to the limit state, was assessed by observing the growth of the plastic zone near the crack tip and analyzing the plots showing the external force $P$ as a function of the load line displacement $v_{L L}[2,3,10]$. The same method of analysis was used both for the 3D cases as well as for the plane stress and plane strain conditions. The relationship between the external load and the load line displacement was plotted for all the analyzed specimens. The plot analysis and the evaluation of the plastic zone were conducted simultaneously $[2,3,10]$. The value of the limit load was determined as the value of the external load read from the plot of the external load $P$ vs. the load line displacement $v_{L L}$, i.e., from the horizontal segment of the $P=f\left(v_{L L}\right)$ curve (plateau on the graph $\left.P=f\left(v_{L L}\right)\right)$, which corresponded to the full plasticity of the uncracked ligament of the specimen $[2,3,10]$. The values of the limit load for 3D SEN(T) plates calculated numerically are provided in Tab.3.

Table 3. Numerical results of the limit load for three-dimensional SEN(T) plates differing in the yield stress, the crack length and the specimen thickness.

\begin{tabular}{|c|c|c|c|c|c|c|c|c|c|c|}
\hline \multirow{3}{*}{$\begin{array}{c}B \\
{[\mathrm{~mm}]}\end{array}$} & \multicolumn{10}{|c|}{$P_{0}[\mathrm{kN}]$} \\
\hline & \multirow{2}{*}{$\begin{array}{c}\sigma_{0} \\
{[\mathrm{MPa}}\end{array}$} & \multicolumn{4}{|c|}{$a / W$} & \multirow{2}{*}{$\begin{array}{c}\sigma_{0} \\
{[\mathrm{MPa}]}\end{array}$} & \multicolumn{4}{|c|}{$a / W$} \\
\hline & & 0.05 & 0.20 & 0.50 & 0.70 & & 0.05 & 0.20 & 0.50 & 0.70 \\
\hline 2 & 315 & 24.15101 & 20.05695 & 12.34691 & 7.556874 & 1000 & 76.55555 & 63.59522 & 39.39672 & 23.83143 \\
\hline 4 & 315 & 48.48864 & 40.32996 & 24.85668 & 15.25735 & 1000 & 153.6674 & 127.8684 & 79.31166 & 48.07711 \\
\hline 8 & 315 & 97.57423 & 81.52093 & 50.2971 & 30.95098 & 1000 & 310.3347 & 258.3944 & 159.0958 & 97.47878 \\
\hline 16 & 315 & 197.2242 & 165.8369 & 102.531 & 63.23182 & 1000 & 625.8454 & 526.1449 & 320.8519 & 196.5381 \\
\hline 25 & 315 & 310.5568 & 262.5115 & 162.8889 & 100.374 & 1000 & 982.3554 & 831.2139 & 510.1782 & 310.9526 \\
\hline 40 & 315 & 499.1794 & 425.7006 & 257.5039 & 160.7705 & 1000 & 1578.269 & 1345.334 & 828.9849 & 499.7293 \\
\hline 2 & 500 & 38.38117 & 31.89821 & 19.70546 & 11.90384 & 1500 & 114.8323 & 95.39284 & 59.09507 & 35.88097 \\
\hline 4 & 500 & 77.70345 & 64.14581 & 39.67075 & 24.01485 & 1500 & 230.5011 & 191.8025 & 118.9675 & 72.40494 \\
\hline 8 & 500 & 155.1857 & 129.555 & 80.27503 & 49.13062 & 1500 & 464.334 & 387.5916 & 235.6942 & 146.8207 \\
\hline 16 & 500 & 312.7091 & 263.6456 & 161.2033 & 100.372 & 1500 & 934.6839 & 788.2095 & 481.6773 & 299.8465 \\
\hline 25 & 500 & 488.6507 & 416.9564 & 256.2036 & 153.666 & 1500 & 1465.177 & 1246.972 & 765.8411 & 463.4406 \\
\hline 40 & 500 & 787.8539 & 673.234 & 414.3284 & 249.9752 & 1500 & 2350.946 & 2024.52 & 1272.692 & 841.5316 \\
\hline
\end{tabular}


Figure 4 presents the influence of the plate thickness, the yield stress and the relative crack length on the limit loads for SEN(T) 3D specimens. From the analysis of the numerical results $[2,3,10]$ it can be concluded that the values of the limit load for thicker specimens are greater than for thinner specimen (Figs 4a-b). The higher the yield stress, the greater the limit load (Figs 4c-d) [2]. An increase in the crack length causes a decrease in the limit load (Figs 4e-f). The analysis of the numerical results indicates that the limit load is proportionally dependent on the yield stress, the specimen thickness and the crack length. These facts will be taken into account in the approximation of the numerical results, which will be discussed in the next section of this paper $[2,3,10]$.

a)

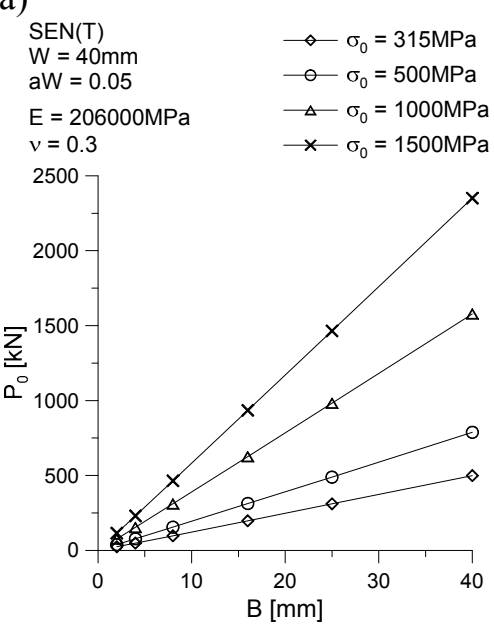

b)

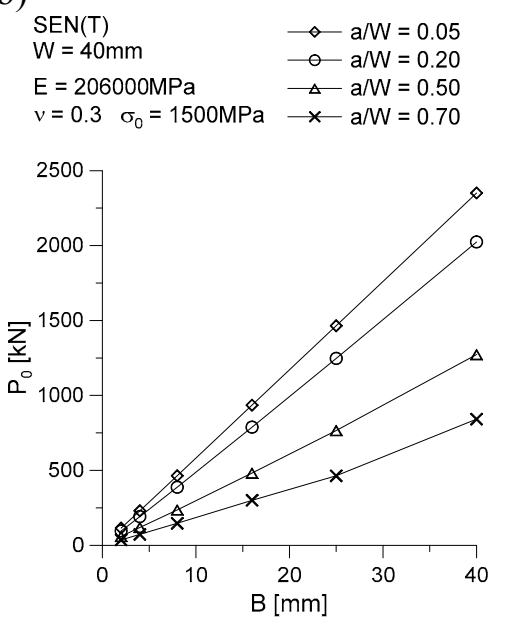

c)

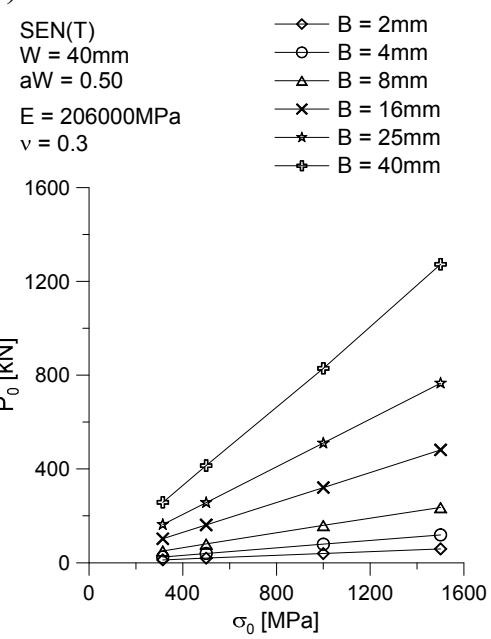

d)

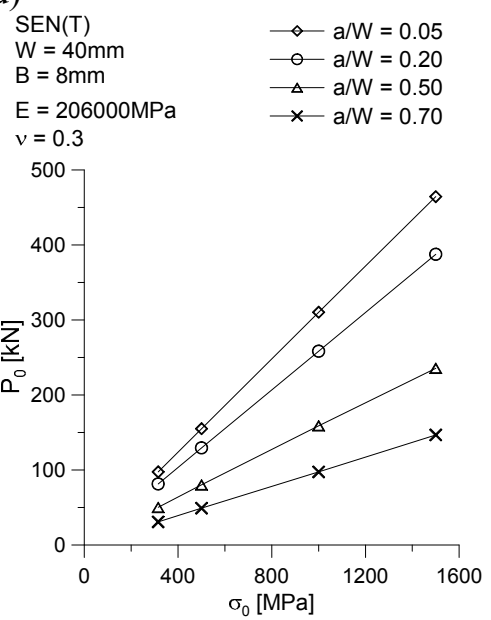

e)

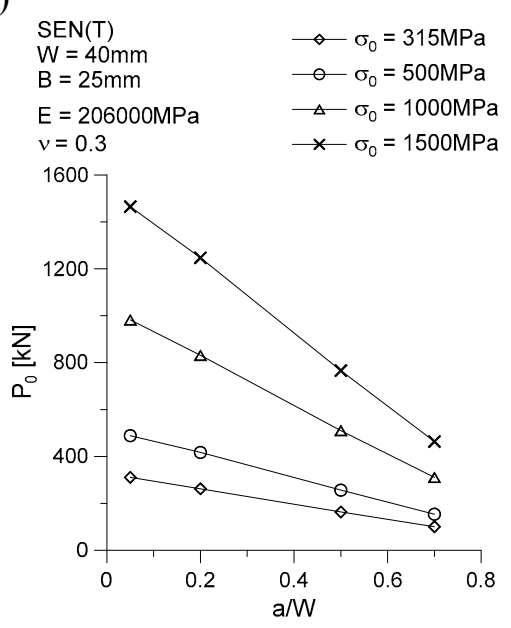

f)

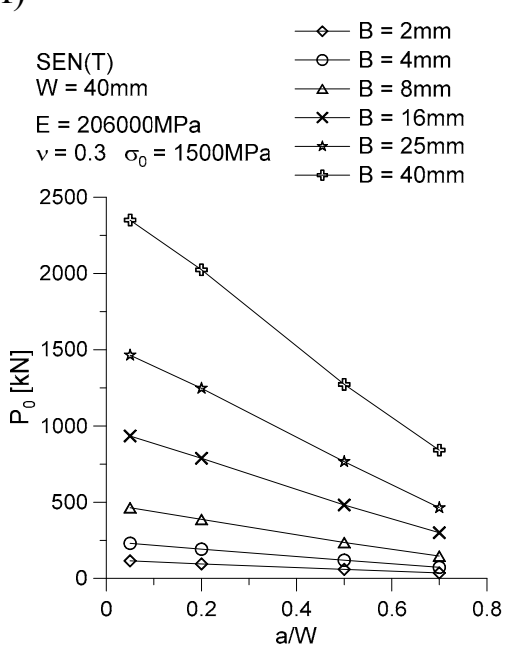

Fig.4. Influence of the plate thickness (a, b), the yield stress (c, d) and the relative crack length on the limit load for SEN(T) plates (3D cases).

For an element under plane stress conditions, the limit load is generally determined using a very thin element with a thickness of $B=1 \mathrm{~mm}$; for the plane strain case, it is assumed that the element thickness is $B=1 \mathrm{~m}$. If there are no results of the FEM-based analysis for a three-dimensional case, the limit load can be calculated using the result obtained for the plane stress or plane strain case multiplied by the element thickness. In this way, it is possible to verify the numerical results for 3D problems. Figure 5a compares the actual values of the load limit for three-dimensional SEN(T) plates under plane stress and plane strain conditions, which were multiplied by the reference value of plate thickness. The analysis reveals that the 
lowest values of the limit load are obtained from the results for the plane stress case; we can say that the results are very conservative, i.e., safe. The highest values of the limit load are obtained when the results for plane strain are used; this approach, however, does not provide conservative results. The results for threedimensional SEN(T) plates range between the results for plane stress and those for plane strain (see Fig.5). Using the limit load to consider 3D engineering problems, we can reduce the level of conservatism, but this solution does not give a maximum stress-strain state of the material. These conclusions are obvious; they confirm the correctness of the calculations.

a)

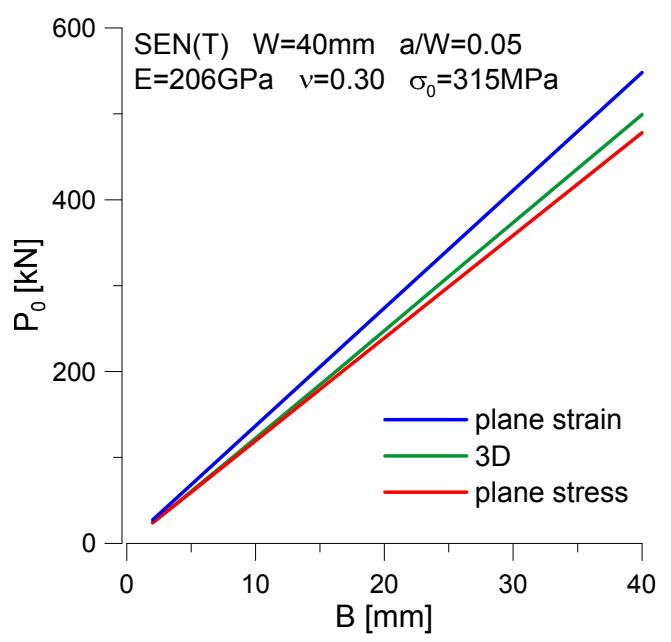

b)

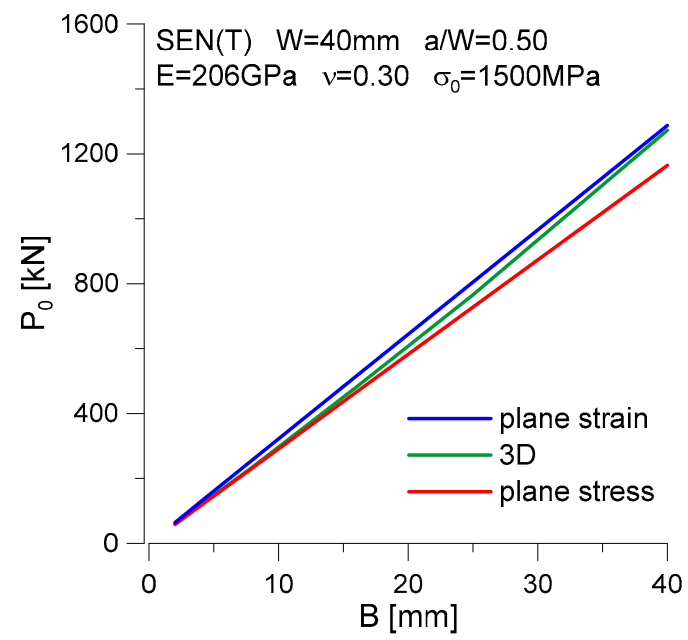

Fig.5. Comparison of the limit load values for $\mathrm{SEN}(\mathrm{T})$ plates (plane strain, 3D cases and plane stress).

\section{Approximation of the numerical results}

From the above simple formulae, used to calculate the limit loads for SEN(T) specimens, new formulae can be derived. Limit loads can be written as a function of the yield stress $\sigma_{0}$, the specimen thickness $B$ and the relative crack length $a / W$ (but the relative crack length $a / W$ can be replaced by the length of the uncracked ligament $b=W-a$ ).

In this paper, new empirical formulae are proposed to calculate the limit loads for $\operatorname{SEN}(\mathrm{T})$ plates under plane stress and plane strain conditions:

for plane stress

$$
\begin{aligned}
& P_{0}=B \cdot \sigma_{0} \cdot f(a / W) \\
& f(a / W)=-0.04037 \cdot(a / W)+0.03976 \quad \text { with } R^{2}=0.99965 \\
& f(a / W)=-0.00566 \cdot(a / W)^{3}+0.01094 \cdot(a / W)^{2}+\quad \text { with } \quad R^{2}=1, \\
& -0.04566 \cdot(a / W)+0.04021
\end{aligned}
$$

for plane strain

$$
\begin{aligned}
& P_{0}=B \cdot \sigma_{0} \cdot f(a / W) \\
& f(a / W)=-47.17113 \cdot(a / W)+45.53878 \quad \text { with } \quad R^{2}=0.99934
\end{aligned}
$$




$$
\begin{aligned}
& f(a / W)=14.848 \cdot(a / W)^{3}-10.27835 \cdot(a / W)^{2}+\text { with } R^{2}=1 . \\
& -47.07730 \cdot(a / W)+45.7481
\end{aligned}
$$

In the above equations, the yield stress should be expressed in [MPa] while the specimen thickness for the plane stress and plane strain cases in $[\mathrm{mm}]$ and $[\mathrm{m}]$, respectively. The limit load $P_{0}$ is calculated in $[\mathrm{kN}]$.

For the 3D cases, another empirical formula was proposed to approximate the numerical results

$$
\begin{aligned}
& P_{0}=(B / W) \cdot \sigma_{0} \cdot f(a / W), \\
& f(a / W)=-1.64828 \cdot(a / W)+1.65906 \quad \text { with } R^{2}=0.998, \\
& f(a / W)=0.02877 \cdot(a / W)^{2}-1.66983 \cdot(a / W)+1.661240 \quad \text { with } \quad R^{2}=0.99921,
\end{aligned}
$$

In Eq.(4.3), the yield stress should be expressed in [MPa] and the limit load $P_{0}$ in [kN].

The above formulae are easy to use. For the plane stress, plane strain and 3D cases, other formulae can be proposed. The formulae are based on three dimensional diagrams showing the changes in the limit load as a function of the yield stress $\sigma_{0}$ and the relative crack length $a / W$ (for plane stress and plane strain) see Fig.6.

a)

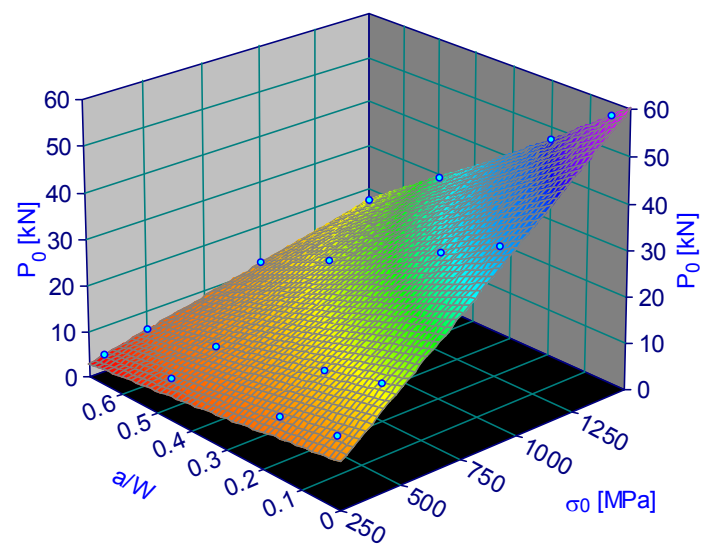

b)

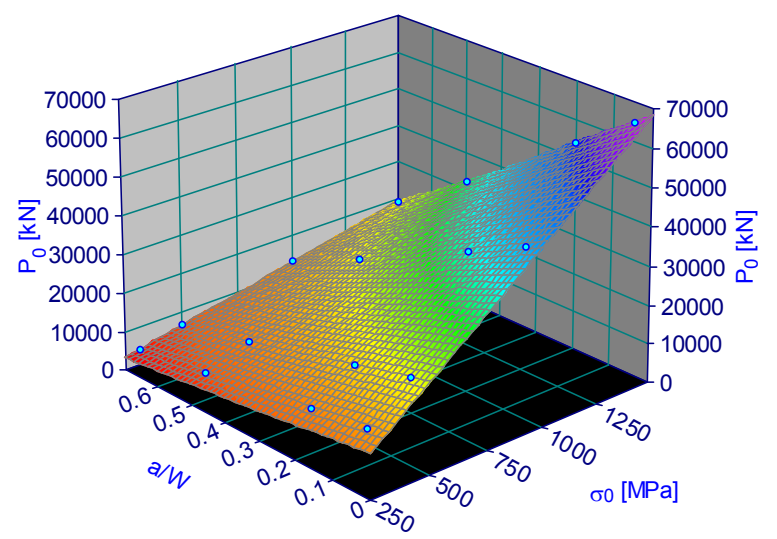

Fig.6. Three-dimensional representation of the limit load for $\operatorname{SEN}(\mathrm{T})$ plates $-P_{0}=f\left(\sigma_{0}, a / W\right)$, for plane stress (a) and plane strain (b).

For the plane stress and plane strain cases the surfaces can be approximated by the following formula

$$
P_{0}=A_{1}+A_{2} \cdot \sigma_{0}+A_{3} \cdot\left(\frac{a}{W}\right)+A_{4} \cdot\left(\sigma_{0}\right)^{2}+A_{5} \cdot\left(\frac{a}{W}\right)^{2}+A_{6} \cdot \sigma_{0} \cdot\left(\frac{a}{W}\right)
$$

where the coefficients $A_{1}, A_{2}, A_{3}, A_{4}, A_{5}, A_{6}$ are given in Tab.4. 
Table 4. Coefficients of approximation of the limit load for SEN(T) plates under plane stress and plane strain conditions, when Eq.(4.4) is used.

\begin{tabular}{|c|c|c|c|c|c|c|c|}
\hline & $A_{1}$ & $A_{2}$ & $A_{3}$ & $A_{4}$ & $A_{5}$ & $A_{6}$ & $R^{2}$ \\
\hline $\begin{array}{l}\text { plane } \\
\text { stress }\end{array}$ & 0.28307353 & 0.039761727 & -2.79729013 & $-6.9695 e-10$ & 3.749443805 & -0.04038697 & 0.9999567376 \\
\hline $\begin{array}{l}\text { plane } \\
\text { strain }\end{array}$ & 422.2384947 & 45.61697129 & -4088.89577 & -0.00013093 & 5279.599951 & -46.9572924 & 0.9999012354 \\
\hline
\end{tabular}

a)

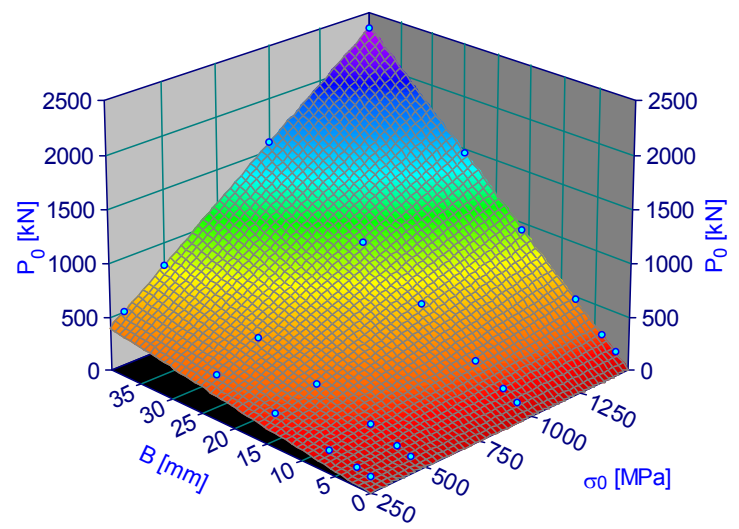

b)

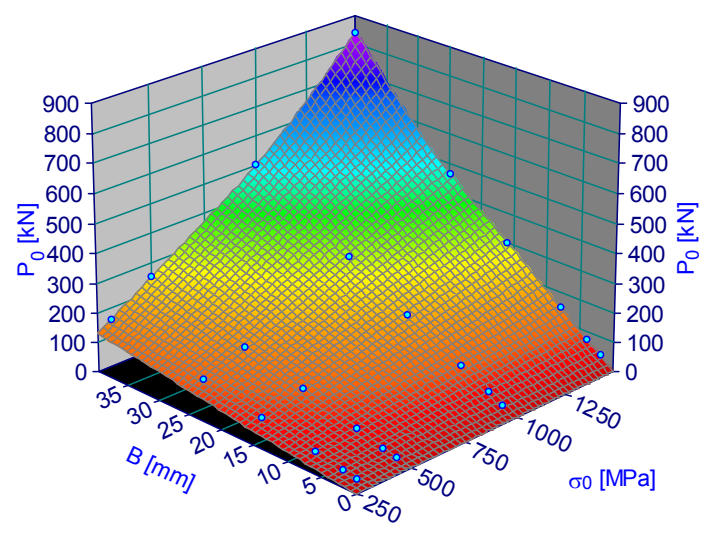

Fig.7. Three-dimensional representation of the limit load values for $3 \mathrm{D} \operatorname{SEN}(\mathrm{T})$ plates $-P_{0}=f\left(\sigma_{0}, B\right)$, for $a / W=0.05$ (a) and $a / W=0.70$ (b).

Table 5. Coefficients of approximation of the limit load for 3D SEN(T) plates, when Eq.(4.5) is used.

\begin{tabular}{|c|c|c|c|c|c|c|c|}
\hline$a / W$ & $A_{1}$ & $A_{2}$ & $A_{3}$ & $A_{4}$ & $A_{5}$ & $A_{6}$ & $R^{2}$ \\
\hline 0.05 & -3.05519416 & 0.009048015 & -0.15264776 & $-6.7802 e-06$ & 0.008156069 & 0.039181601 & 0.9999920216 \\
\hline 0.20 & 7.147670856 & -0.01353248 & -1.01534951 & $1.94915 e-06$ & 0.024312039 & 0.033831376 & 0.9999735328 \\
\hline 0.50 & 13.87331683 & -0.02434545 & -1.44307791 & $6.94951 e-06$ & 0.027128338 & 0.021353732 & 0.9997358213 \\
\hline 0.70 & 31.32321605 & -0.0648562 & -2.25174024 & $2.7103 e-05$ & 0.036013231 & 0.014107603 & 0.9965975144 \\
\hline
\end{tabular}

For 3D cases, a similar formula was proposed. It was based on three-dimensional plots showing changes in the limit load as a function of yield stress $\sigma_{0}$ and plate thickness $B$ for different relative crack lengths $a / W$ (Fig.7)

$$
P_{0}=A_{1}+A_{2} \cdot \sigma_{0}+A_{3} \cdot B+A_{4} \cdot\left(\sigma_{0}\right)^{2}+A_{5} \cdot B^{2}+A_{6} \cdot \sigma_{0} \cdot B
$$

where the coefficients $A_{1}, A_{2}, A_{3}, A_{4}, A_{5}, A_{6}$ are presented in Tab.5.

\section{Conclusions}

This paper is a continuation of the author's previous studies. In this paper, the existing limit load solutions for SEN(T) specimens have been briefly discussed. Numerical calculations were used to verify the existing limit load solutions for SEN(T) specimens and to expand the limit load theory to 3D cases $[2,3,10]$. Four elastic-perfectly plastic materials and four relative crack lengths were considered $[2,3,10]$. The numerical results were represented in the tabular and graphical forms. The conclusions drawn from the analysis of the numerical results are presented in $[2,3,10]$. New alternative approximation formulae were 
proposed to calculate the limit load for all the analyzed cases - plane stress, plane strain, 3D. The approximation formulae can be used to solve practical engineering problems.

\section{Acknowledgements}

The research reported herein was supported by a IUVENTUS PLUS grant from the Ministry of Science and Higher Education (No. IP2012 011872).

\section{Nomenclature}

2D - two dimensional

3D - three dimensional

$A_{1} . . A_{6}$ - coefficients of approximation

$a$ - crack length $[\mathrm{m}]$

$a / W$ - relative crack length

$B$ - specimen thickness $[\mathrm{m}]$

$b$ - length of the uncracked ligament, $b=W-a[m]$

CDF - Crack Driving Force Diagram

E - Young's modulus [MPa]

EPRI - Electric Power Research Institute

FAD - Failure Assessment Diagram

FEM - Finite Element Method

$f(a / W)$ - geometry function used for the approximation of the numerical results

$J-J$-integral $[N / m]$

$L$ - specimen length $[m]$

$P$ - external load $[\mathrm{kN}]$

$P_{0}$ - limit load $[k N]$

$r_{w}-$ radius of the arc in crack tip $[\mathrm{m}]$

SEN $(\mathrm{T})$ - single edge notched plate in tension

$v_{L L}-$ load line displacement $[\mathrm{m}]$

$W$ - specimen width $[m]$

$x_{1}, x_{2}, x_{3}-$ Cartesian coordinates: $x_{1}, x_{2}-$ in the crack plane, $x_{3}-$ in the thickness direction

$x_{3} / B$ - normalized coordinate in the thickness direction $\left(x_{3} / B=0\right.$ - center of the specimen, $x_{3} / B=0.5-$ free surface of the specimen)

$\Delta_{P 0}-$ difference between the numerical solution and the existing approximation, $\left.\Delta_{P 0}=\left(P_{O_{-F E M}} P_{O_{-} E Q(5)}\right) / P_{0_{-} F E M}\right) \cdot 100 \%$

$\eta$ - geometry function, $\eta=\left[1+(a / b)^{2}\right]^{0.5}-(a / b)$

$v$ - Poisson's ratio

$\sigma_{0}-$ yield stress $[\mathrm{MPa}]$

\section{References}

[1] Neimitz A., Dzioba I., Graba M. and Okrajni J. (2008): The assessment of the strength and safety of the operation high temperature components containing crack. - Kielce University of Technology Publishing House, Kielce (in Polish).

[2] Graba M. (2013): Numerical verification of the limit load solutions for single edge notch specimen in tension.Archives of Civil and Mechanical Engineering, vol.13, No.1, pp.45-56.

[3] Graba M. (2013): Extension of the concept of limit loads for 3D cases for a centrally cracked plate in tension.Journal of Theoretical and Applied Mechanics, vol.51, No.2, pp.349-362.

[4] Graba M. (2009): Numerical analysis of the mechanical fields near the crack tip in the elastic-plastic materials. $3 D$ problems. - PhD Dissertation, Kielce University of Technology - Faculty of Mechatronics and Machine Building , 387 pages, Kielce 2009 (in Polish). 
[5] Kumar V., German M.D. and Shih C.F. (1981): An engineering approach for elastic-plastic fracture analysis. Electric Power Research Institute, Inc. Palo Alto, CA (1981), EPRI Report NP-1931.

[6] Miller A.G. (1988): Review of limit loads of structures containing defects. - International Journal of Pressure Vessels and Piping, vol.32, pp.197-327.

[7] Chauhan S., Chattopadhyay J. and Dutta B.K. (2016): Limit load equations for miniature single edge notched tensile specimens. - Transactions of the Indian Institute of Metals, March 2016, vol.69, No.2, pp 641-646.

[8] ADINA, 2008a, ADINA 8.7.3: ADINA: Theory and Modeling Guide - Volume I: ADINA, Report ARD 08-7, ADINA R\&D, Inc., 2008.

[9] ADINA 2008b, ADINA 8.7.3: ADINA: User Interface Command Reference Manual - Volume I: ADINA Solids \& Structures Model Definition, Report ARD 08-6, ADINA R\&D, Inc., 2008.

[10] Graba M. (2016): Numerical verification of the fully plastic solution and elastic-plastic estimation formulas for double edge notch plate in tension (forthcoming).

[11] Brocks W., Cornec A., Scheider I. (2003): Computational aspects of nonlinear fracture mechanics. Bruchmechanik, GKSS-Forschungszentrum, Geesthacht, Germany, Elsevier pp.127-209.

[12] Brocks W. and Scheider I. (2003): Reliable J-values. Numerical aspects of the path-dependence of the J-integral in incremental plasticity. - Bruchmechanik, GKSS-Forschungszentrum, Geesthacht, Germany, Elsevier pp.127-209.

[13] Graba M. and Gałkiewicz J. (2007): Influence of the crack tip model on results of the finite element method. Journal of Theoretical and Applied Mechanics, Warsaw, vol.45, No.2, pp.225-237.

[14] Kim Y., Zhu X.K. and Chao Y.J. (2001): Quantification of constraint on elastic-plastic $3 D$ crack front by the J-A2 three-term solution. - Engineering Fracture Mechanics, vol.68, pp.895-914.

[15] Kim Y., Chao Y.J. and Zhu X.K. (2003): Effect of specimen size and crack depth on 3D crack-front constraint for SENB specimens. - International Journal of Solids and Structures, vol.40, pp.6267-6284.

Received: April 28, 2016

Revised: May 9, 2016 